\title{
Accuracy of Trajectory Tracking Based on Nonlinear Guidance Logic for Hydrographic Unmanned Surface Vessels
}

\author{
Andrzej Stateczny ${ }^{1}\left(\mathbb{C}\right.$, Pawel Burdziakowski ${ }^{1, *} \mathbb{B}$, Klaudia Najdecka ${ }^{2}$ and \\ Beata Domagalska-Stateczna ${ }^{2}$ \\ 1 Department of Geodesy, Faculty of Civil and Environmental Engineering, Gdansk University of Technology, \\ Narutowicza 11-12, 80-233 Gdansk, Poland; andrzej.stateczny@pg.edu.pl \\ 2 Marine Technology Ltd., Roszczynialskiego 4/6, 81-521 Gdynia, Poland; \\ k.najdecka@marinetechnology.pl (K.N.); b.domagalska@marinetechnology.pl (B.D.-S.) \\ * Correspondence: pawel.burdziakowski@pg.edu.pl
}

Received: 6 January 2020; Accepted: 2 February 2020; Published: 4 February 2020

check for updates

\begin{abstract}
A new trend in recent years for hydrographic measurement in water bodies is the use of unmanned surface vehicles (USVs). In the process of navigation by USVs, it is particularly important to control position precisely on the measuring profile. Precise navigation with respect to the measuring profile avoids registration of redundant data and thus saves time and survey costs. This article addresses the issue of precise navigation of the hydrographic unit on the measuring profile with the use of a nonlinear adaptive autopilot. The results of experiments concerning hydrographic measurements performed in real conditions using an USV are discussed.
\end{abstract}

Keywords: trajectory tracking; unmanned surface vehicle; navigation; bathymetry; hydrographic survey

\section{Introduction}

The importance of hydrographic measurement in recent years has been growing constantly due to the increasing use of water transport, including movements in restricted areas. A particular challenge is shallow-water measurements near land or navigational obstacles where the use of larger hydrographic units is impracticable or not justified economically. An important aspect in this respect is the desire to shift loads from roads and motorways to waterways, which, by definition, are safer and transport is more ecologically friendly and economical.

The process of conducting hydrographic measurements in land-restricted waterways requires precise acquisition of the measurement profile, and a limit to the acquisition of redundant data on the measurement strip tabs in the case of multi-beam echosounder (MBES) measurements and excessive gaps between measurement profiles in the case of single-beam sonar measurements. The International Hydrographic Organization (IHO) does not define the accuracy of maintaining the measuring unit on the profile, but only determines the percentage of searching the bottom of the reservoir and the accuracy of determining the position of the measuring unit. For instance, in the case of the most restrictive special category, $100 \%$ coverage and an accuracy of $2 \mathrm{~m}$ with respect to determination of position with a $95 \%$ confidence level is required [1].

Traditionally, for manned hydrographic units, the helmsman follows the position of the unit on the profile on the monitor screen of the measurement system, adjusting the parameters of the unit's movement to the current weather conditions. Many measurement systems used throughout the world provide the helmsman with an indicator which shows the current distance from the planned measurement profile. Continuous tracking of the position of the measuring unit on the profile requires a high degree of concentration and an appropriate response from the helmsman; this is a tedious and 
challenging task. It requires a relatively frequent change of the watch in the case of the helmsman controlling the hydrographic unit.

A disadvantage of manual control is also the quite low accuracy of maintaining the measuring unit on the profile and a moment of inattention or distraction may result in deviation from the measuring profile thus requiring repetition of registration on the incorrectly registered profile. For this reason, significant amounts of redundant data are recorded, which hamper the processing of the measurement data. The issue of achieving precise control of the measurement profile on a hydrographic unit can be solved by using an unmanned surface vehicle (USV) with an adaptive autopilot which realizes precise control of both course and speed.

Generally, unmanned mobile platforms, including surface, aerial, and ground vehicles have been increasingly employed for numerous operations. Currently, the unmanned platforms are widely used around the world, giving rise to many new research opportunities. In this context, various control schemes have been also developed to perform predefined tasks. Unmanned surface vessels suffer from many uncertainties and unknown external disturbances like winds, waves, currents, etc., which inevitably lead to a very challenging task [2] like accurate trajectory tracking within this complex navigation environment [3]. Due to this, various advanced control techniques and schemes for surface vehicles have been developed, and the following groups can be highlighted: backstepping technique [4-7], chaos control approach [8-10], fuzzy control [2,3,11,12], neural control [13-18], and finite-time control [19-21].

This paper considers the problems of precise control of the measurement profile on a hydrographic unit using a nonlinear adaptive autopilot originally designed for unmanned aerial vehicles. The results of experiments carried out under real conditions are presented.

\section{Trajectory Tracking}

Precise tracking of the trajectory during maneuvering is very important, especially for an autonomous multi-purpose water platform [22,23] engaged in hydrographic survey missions of restricted access areas like ports, embankments, anchorages, bays and lakes, and rivers. Generally, in such areas, maneuvering requires execution of precise, previously planned track information. Additionally, in any difficult navigational situation such as caused by recreational boats and other traffic, precise execution of the planned or preplanned track becomes crucial.

The evaluated track following method, termed guidance logic, was designed originally for aerial applications [24] and unmanned aerial vehicles (UAVs) and was successfully implemented in many UAV applications [24-26]. This approach is also used by small unmanned surface vessels [27-29]; however, the platforms applied in that research are significantly smaller than the platform used in the present work. Studies on autonomous navigation algorithms and navigation strategies have been reported [30-32] while interesting studies for an adaptive system for steering strategy are available [33-35]. Aspects on the safety of vehicle navigation have been discussed [36-38] while actual problems concerning control of trajectory tracking for marine vehicles have also been reported [2-21,39,40].

An outline of the steps and the computer programing methods used for trajectory tracking is given in Figure 1. Implementation follows that of a previous study [41] and where the mission control module is similar to a system described elsewhere [22]. 
where the desired point is on the planned track at distance $L_{1}$ from the actual origin of the vehicle (Figure 2). Knowing that:

$$
L_{1}=2 R \sin \eta
$$

where the lateral acceleration calculated by Equation (1) equals the centripetal acceleration required to follow instantaneously a circular segment and $a_{S}$ is the property used to track a circle of any radius $R$. This characteristic predisposes the guidance logic to work faithfully with a curved path. Moreover, as shown elsewhere [24], the method shows better capabilities than the PID controller when used on the $\mathrm{UAV}$ in the presence of wind. In this research, the method will be examined on the unmanned surface vessel (USV) using state-of-the-art geodetic grade measurements. The reference position of the USV was measured using independently acquired GPS navigation data (GPS RTK (Real Time Kinematic) geodetic receiver).

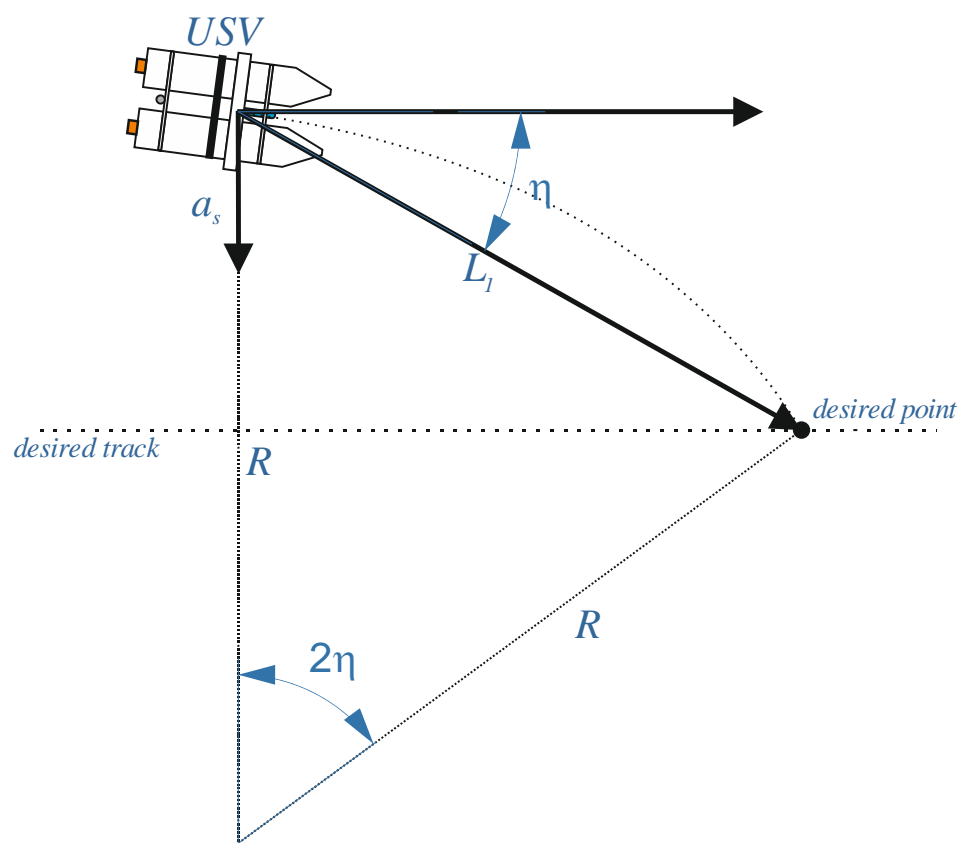

Figure 2. Guidance logic trajectory tracking.

The original Equations (1) and (2) were modified [41] for USV navigation purposes. The implementation required the addition of two parameters ( $L_{1}$ Damping Factor and $L_{1}$ Period). Therefore, for the new $L_{1}$ :

$$
L_{1 t}=\frac{1}{\pi} \zeta T v
$$

$\zeta$ is the $L_{1}$ Damping Factor, $T$ is the $L_{1}$ Period (s), and $v$ is the speed of the unit. Finally, substituting Equation (3) into Equation (1) can be written as:

$$
a_{s t}=\frac{\mathrm{k} v^{2}}{L_{1 \mathrm{t}}} \sin \left(\eta_{1}-\eta_{2}\right)
$$

where $k$ is the $L_{1}$ Control Gain, defined as:

$$
\mathrm{k}=4 \zeta^{2}
$$

The cross-track error (XTE), corresponding to $l_{\perp}$ on Figure 3 and defined as a distance between actual USV position perpendicular to the intended (desired) track, can be approximated as a second order differential equation [42]:

$$
\ddot{d}+2 \zeta \omega_{n} \dot{d}+\omega_{n}^{2} d=0
$$


where the natural frequency $\omega_{n}$ (natural frequency (eigenfrequency) is the frequency at which a structure or system have the tendency to oscillate in the absence of any driving or damping forces), is related to $T$ :

$$
\omega_{n}=\frac{2 \pi}{T}
$$

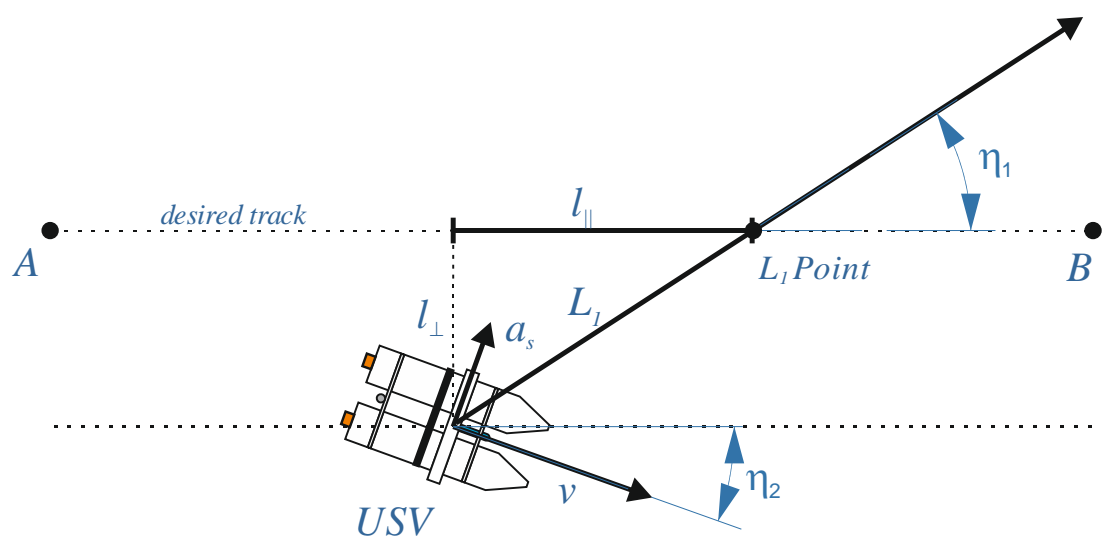

Figure 3. Guidance logic trajectory tracking for an unmanned surface vehicle (USV).

The dynamics of Equation (6) indicate that changing the values of $\zeta$ and $\omega_{n}$ adjusts the control response of XTE. The $\zeta$ and $\omega_{n}$ values are specified by the user and, for this research, were adjusted experimentally after long and extensive trials.

The parameter tuning requires some user experience regarding the USV'S parameters and the response observations during the trials. As a general rule for tuning, the following instructions are given. The $L_{1}$ period $T$ is given in seconds with a range from 1 to 60 (increments of 1 ) for the $L_{1}$ tracking loop and is the primary control parameter for aggressive turns in auto mode (Figure 1). This parameter should be larger for less responsive USV platforms. For smaller and more maneuverable USVs a lesser value can be set. The starting value was adjusted experimentally as $20 \mathrm{~s}$. The $L_{1}$ control damping ratio $\zeta$ with range from 0.6 to 1 (increments of 0.05 ) should be increased if the USV overshoots the track being followed.

Significant changes made to the original Equation (1) enable the length $L_{1}$ to be calculated dynamically by the navigation loop depending on the USV ground speed changes and enable the user to specify a constant period for the tracking loop.

The L1 Control Gain was changed from a fixed value of 2 (Equation (1)) to be calculated based on the $\zeta$ value set by the user. This enables additional damping to be specified to compensate for delays in the velocity measurement and for the USV frame to respond.

Figure 4 presents all possible tracking movements. The current tracking mode depends on the area where the USV is located in relation to the route plan. Figure 4 presents a simple survey plan based on 6 WPs. When the vehicle is located in $U S V_{1}$, the first WP is acknowledged to be tracked and vehicle i proceeds to point $A$. The point is considered to be reached when the unit is within the $W P_{\text {Radius }}$ parameter. The $W P_{\text {Radius }}$ is the distance in meters from a WP when the algorithm considers the WP has been reached and determines when the unit will proceed to the next WP. After reaching the first WP, the unit starts the L1 tracking mode (positions $U S V_{2}, U S V_{4}$ ). In the L1 tracking mode a point $\mathrm{L}$ is tracked and this point is dynamically located on the line between the last and next WP. The L point is the intersection point between the track line and the circle with the radius equal to the distance $L_{1}$ defined by the user. When point B is reached the next WP $(C)$ is acknowledged to be tracked (Next WP Tracking Area). The procedure is repeated until the unit reaches the last WP when it stops and waits for the next command, either from the operator or the autonomous system. 


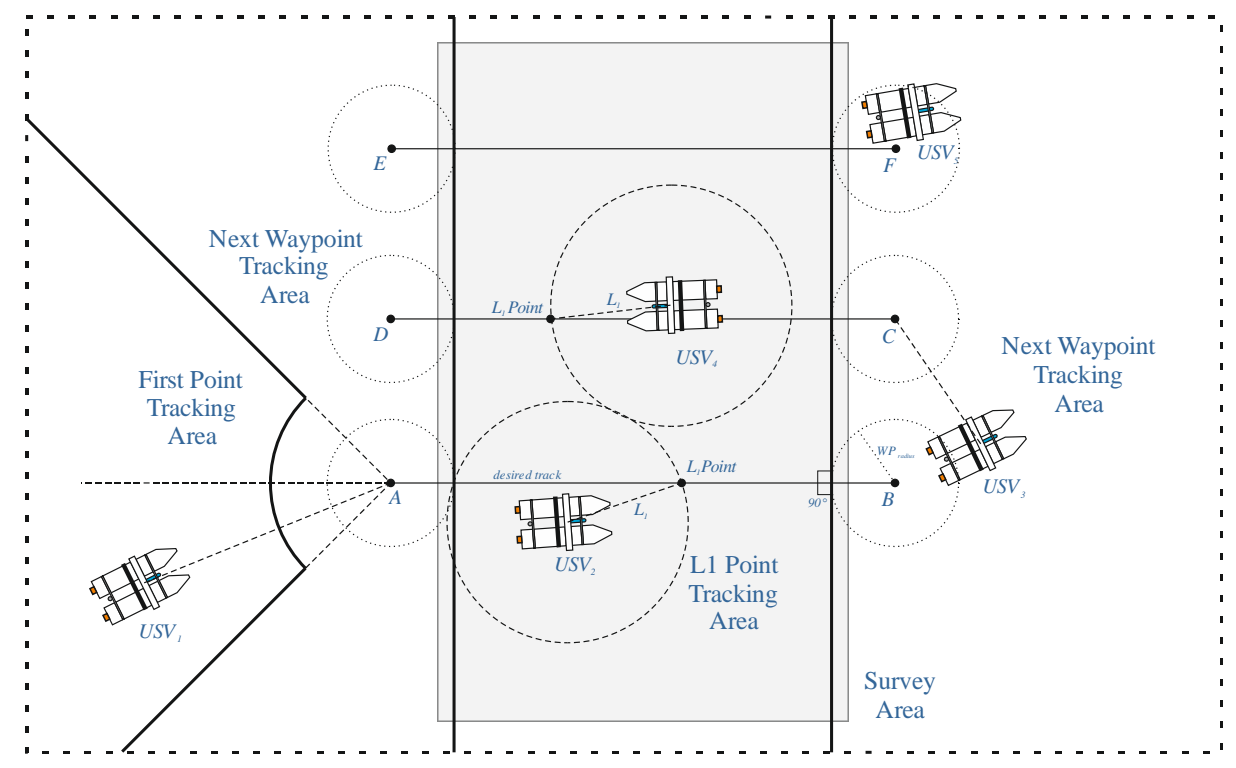

Figure 4. Tracking areas for USV hydrographic survey using L1 controller.

The L1 method calculates the lateral acceleration to be executed by the unit. The $L_{1}$ acceleration is translated to the motors and the steer command using the Steering LA and Motor Control methods (Figure 1). The Steering LA method is based on a PID controller. The automatic (mission control) algorithms, according to research [25] were demonstrated to control speed and course of the surface vessel. The PID controller continuously attempts to minimize the error $e(t)$ over time by adjustment of a control variable $u(t)$. The error value function $e(t)$ is the difference between a desired set point $r(t)$ and the measured process variable $y(t)(e(t)=r(t)-y(t))$. Process variable is represented by the value that is being controlled (e.g., actual speed or actual course). The PID controller can be expressed as:

$$
\mathrm{u}(\mathrm{t})=\mathrm{K}_{\mathrm{p}} \mathrm{e}(\mathrm{t})+\frac{1}{\mathrm{~T}_{\mathrm{i}}} \int_{0}^{\mathrm{t}} \mathrm{e}(\mathrm{t}) \mathrm{dt}+\mathrm{T}_{\mathrm{d}} \frac{\mathrm{de}(\mathrm{t})}{\mathrm{dt}}
$$

where $K_{p}, K_{i}$, and $K_{d}$ are non-negative and denote the coefficients for the proportional, integral, and derivative terms, respectively. The parameters were set experimentally during test trials. The PID desired and the PID achieved were monitored and displayed and the coefficients can be adjusted to achieve the appropriate object response and parameter (course and speed) stabilization.

\section{System Specification}

The steering system specification for the unit (Table 1) is based on a combination of skid steering and a traditional rudder (Figure 5).

Table 1. USV technical specification.

\begin{tabular}{ll}
\hline Specification & Data \\
\hline Dimensions $(\mathrm{L} \times \mathrm{W} \times \mathrm{H})$ & $4230 \times 2080 \times 1390 \mathrm{~mm}$ \\
Draft & $500 \mathrm{~mm}$ \\
Weight & $360 \mathrm{~kg}$ \\
Power supply & $48 \mathrm{~V} 200$ Ah lithium iron phosphate battery $\left(\mathrm{LiFePO}_{4}\right)(16 \mathrm{cells})$ for \\
Endurance & propulsion, $24 \mathrm{~V}$ lead-acid battery for electronics \\
Motors & $12 \mathrm{~h}($ cruise speed) \\
Remote control range & $2 \times$ Torqeedo Cruise 4.0 \\
Telemetry data range & $40 \mathrm{~km}$ \\
Payload data range & $50 \mathrm{~km}$ \\
Max speed & $6 \mathrm{~km}$ \\
\hline
\end{tabular}




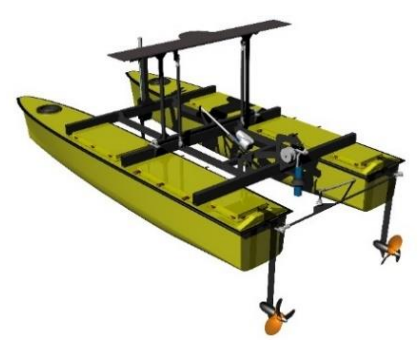

(a)

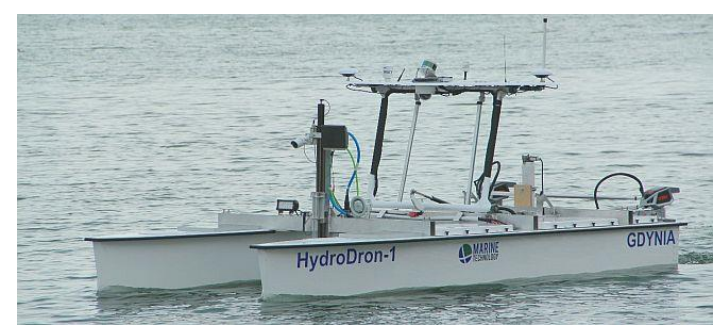

(b)

Figure 5. Combined skid and traditional steering system-motors and rudder design plan (a), photo of USV HydroDron during experiments (b).

Skid-Steering is a type of vehicle steering where rotation (yaw) is obtained by a difference in the speeds of the left and right propellers (wheel) and is typical for vehicles with non-orientable propellers (wheels). Electric motors installed on the platform and situated in the right hull are turned using a linear actuator, therefore, maneuverability is enhanced, and the unit is more responsive to steering, when compared to steering using only pure skid steering. Additionally, this USV uses pivot turns when the angle of turn is greater than a specific angle (can be set in the Pivot Turn Angle parameter). The pivot turn angle was selected as a result of extensive trials and was equal to $45^{\circ}$.

The USV is equipped with an autopilot and the navigation position is calculated based on the autopilot's internal sensors: three magnetic compasses (nine MEMS magnetometers), an inertial navigation system (INS) based on simple MEMS (microelectromechanical system) sensors consisting of nine gyroscopes and nine accelerometers (compasses and INS embedded in autopilot) and an external GNSS receiver based on an UBlox M8N module. In that configuration, the USV position is calculated using an EKF (extended Kalman filter). The EKF is a 24-state extended Kalman filter and the autopilot's filter estimates the following states: altitude, velocity, position, gyro bias offsets, gyro scale factors, $\mathrm{Z}$ accel. bias, Earth's magnetic field, platform body magnetic field, and wind velocity. For calculations in this study, the navigation autopilot used the EKF output position, which means that this was not a pure GPS reading, but filtered and estimated based on other internal sensors. Only one GNSS module based on the UBlox M8N module was used (Table 2).

Table 2. Navigation GPS specification.

\begin{tabular}{cc}
\hline Parameter Name & Specification \\
\hline Channels & 72 \\
\hline Signal tracking: & GPS: L1C/A \\
& SBAS: L1C/A \\
& QZSS: L1C/A \\
& GLONASS: L1OF \\
BeiDou: B1 & Galileo: E1B/C2 \\
\hline Horizontal position accuracy ${ }^{1}$ & GPS and GLONAS: $2.5 \mathrm{~m}$ \\
Velocity accuracy ${ }^{2}$ & SBAS: $2.0 \mathrm{~m}$ \\
\hline True heading accuracy ${ }^{2}$ & $0.05 \mathrm{~m} / \mathrm{s}$ \\
\hline & $0.3^{\circ}$ \\
\hline Operating limits & Altitude: $50,000 \mathrm{~m}$ \\
& Velocity: $500 \mathrm{~m} / \mathrm{s}$ \\
\hline Time to first fix & Acceleration: $4 \mathrm{~g}$ \\
\hline Max output frequency & Cold start: $<26 \mathrm{~s}$ \\
& Warm start: $<1 \mathrm{~s}$ \\
\hline 1 CEP, $50 \%, 24 \mathrm{~h}$ static, $-130 \mathrm{dBm},>6$ SVs; ${ }^{2} 50 \%$ at $30 \mathrm{~m} / \mathrm{s}$.
\end{tabular}


The GPS RTK module readings are not used for navigation; the module is part of the hydrographic equipment and additionally, the acquired RTK readings were used as a reference and as an independent USV position registration. The GPS RTK receiver specifications are given in Table 3. The GPS RTK used for position registration was a state-of-the-art survey grade receiver, embedded in the SPLITBOX-STD-T hydrographic equipment and based on the Trimble GNSS receiver.

Table 3. GPS RTK specification.

\begin{tabular}{cc}
\hline Parameter Name & Specification \\
\hline Channels & 220 \\
& GPS: L1 C/A, L2E, L2C, L5 \\
Signal tracking & GLONASS: L1 C/A, L2 C/A, L2 P, L3 CDMA \\
& Galileo: 1 BOC, E5A, E5B, E5AltBOC \\
& Beidou B1, B2 \\
SBAS, QZSS \\
L-Band OmniSTAR VBS, HP, XP \\
\hline Horizontal position accuracy & SBAS/DGPS: $0.5 \mathrm{~m} / 0.25 \mathrm{~m}$ \\
(1 sigma) & PPP: $10 \mathrm{~cm}$ \\
\hline Velocity accuracy & RTK: $0.8 \mathrm{~cm}+1 \mathrm{ppm}$ \\
\hline True heading accuracy & $0.7 \mathrm{~cm} / \mathrm{s} \mathrm{RMS}$ \\
\hline Operating limits & $0.09^{\circ}$ at $2 \mathrm{~m}$ baseline \\
& $0.05^{\circ}$ at $10 \mathrm{~m}$ baseline \\
\hline Time to first fix & Altitude: $18,000 \mathrm{~m}$ \\
Signal reacquisition & Velocity: $515 \mathrm{~m} / \mathrm{s}$ \\
\hline Max output frequency & Acceleration: $11 \mathrm{~g}$ \\
\hline & Cold start: $<45 \mathrm{~s}$ \\
\hline & Warm start: $<30 \mathrm{~s}$ \\
\hline & L1/L2/L5: $<2.0 \mathrm{~s}$ \\
\hline & $50 \mathrm{~Hz}$ \\
\hline
\end{tabular}

\section{Experiments}

The experiments were divided into three phases. Phase one was data acquisition. In this phase three different patterns were planned and executed. The patterns were planned to represent typical hydrographic surveys based on the present unit (Pattern 1) (Figure 6) and the bottom object investigation plan (Patterns 2 and 3) (Figure 6). All the profiles were numbered in accordance with their execution order. Profiles 1 to 10 belong to pattern no. 1, profiles from 11 to 14 belong to pattern no. 2, and profiles from 15 to 19 belong to pattern no. 3. All data were recorded within their typical hardware configuration, meaning that no additional technical rearrangements of the unit were conducted. The unit in this configuration was prepared to undertake surveys based on best knowledge and practice including use of state-of-the-art hydrographic equipment, therefore, all equipment was calibrated, and all GNSS and INS equipment offsets were measured, and data entered into all hardware units.

Phase two of the experiment concerned logged data filtration and preparation and evaluation of navigation GPS accuracy in the dynamic measurements. To prepare for this evaluation, studies described elsewhere [1] were used.

The approach used the PL-2000 system (ETRS89/Poland CS2000 zone 6) which afforded the replacement of angular coordinates recorded by the GPS and RTK by Cartesian coordinates (in meters). This conversion (from angular GPS coordinates to Cartesian) allowed the calculations to be simplified and the results to be presented in meters. The PL-2000 coordinate system is Cartesian 2D coordinate system with northing $(\mathrm{x})$ and easting $(\mathrm{y})$ axes with orientations fixed to north, east, and units of measurement in meters. 

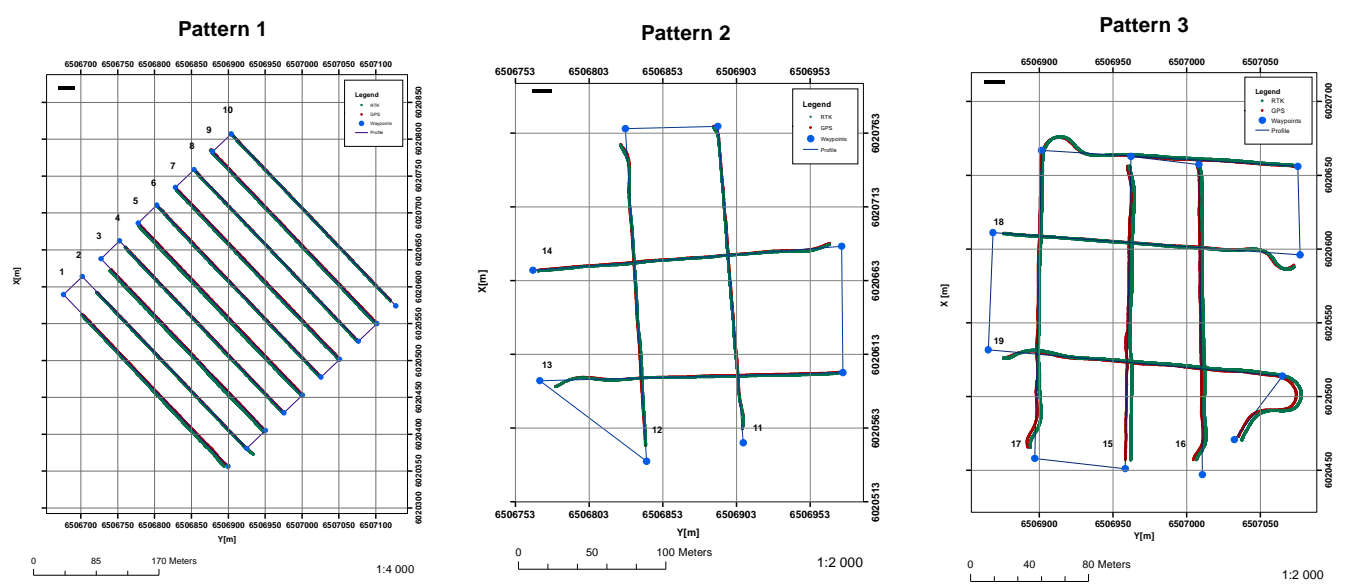

Figure 6. Survey pattern plans.

\subsection{Data Synchronization}

Navigation GPS maximal output frequency was declared as $5 \mathrm{~Hz}$, which means that the GPS position $\left(p_{G P S}\right)$ was reported a maximum of five times per second (Figure 7a). To compare both the registered tracks, i.e., RTK and GPS, the data rate for both RTK and GPS should be the same (Figure 7b). However, the RTK system reported position $\left(p_{R T K}\right)$ with a maximum of 50 points every second and in fact both systems registered tracks at different rates.

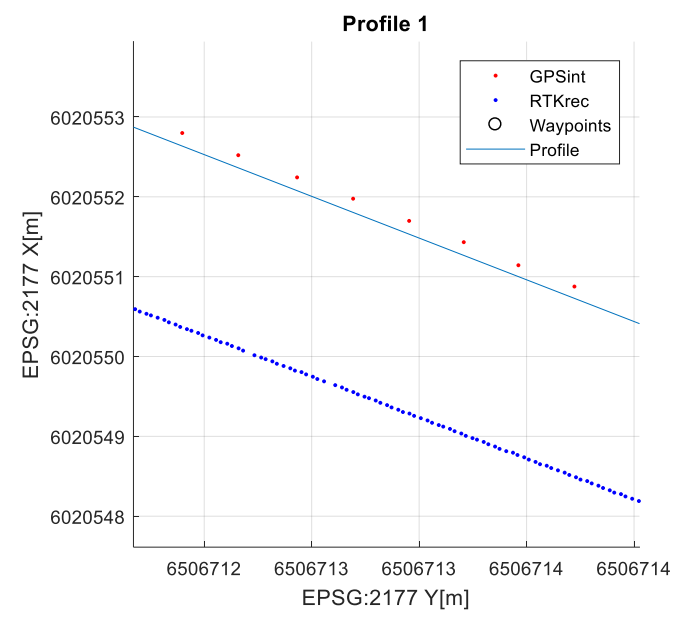

(a)

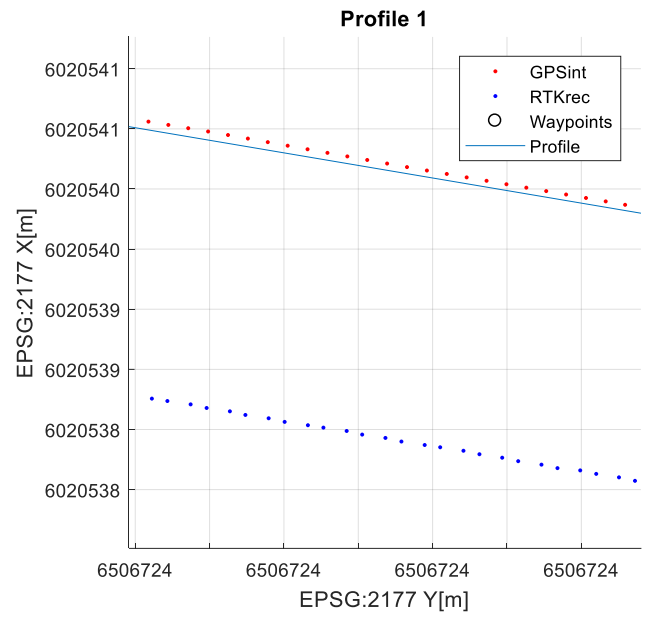

(b)

Figure 7. Recorded GPS and RTK tracks (a) different frequency (b) interpolated GPS positions.

To align the track rates a linear interpolation was applied to the lower rate track, i.e., the GPS track. All GPS positions $\left(p_{G P S}\right)$ were interpolated with the maximum number of points equal to that for the RTK $\left(p_{R T K}\right)$.

Assuming a data set consisting of independent data values $x_{i}$ and dependent data values $y_{i}$, where $x=1, \ldots, n$, we can find an interpolation function $\hat{y}(x)$ such that $\hat{y}\left(x_{i}\right)=y_{i}$ for every point in our data set. This means that the interpolation function goes through the given data points. Given a new $x *$ we can interpolate its function value using $\hat{y}(x *)$ [43]. In the present study, a linear interpolation was used.

The estimated positions are assumed to lie on the line joining the nearest registered positions of the estimated track with $n_{\text {GPS }}$ registered positions. It is assumed, without loss of generality, that the 
GPS coordinates transformed to PL-2000 $\left(X_{G}\right.$ and $\left.Y_{G}\right)$ are in ascending order, then new interpolated position coordinates $\hat{X}_{\mathrm{G}_{\mathrm{i}}}$ and $\hat{Y}_{\mathrm{G}_{\mathrm{i}}}$ are calculated according to:

$$
\begin{aligned}
& \hat{X}_{G_{\mathrm{i}}}=X_{\mathrm{G}_{\mathrm{i}}}+\frac{\left(\mathrm{X}_{G_{i+1}}-\mathrm{X}_{G_{i}}\right)\left(n_{R}-n_{\mathrm{G}}\right)}{\left(n_{G+1}-n_{G}\right)} \\
& \hat{Y}_{\mathrm{G}_{\mathrm{i}}}=Y_{\mathrm{G}_{\mathrm{i}}}+\frac{\left(\mathrm{Y}_{G_{i+1}}-\mathrm{Y}_{G_{i}}\right)\left(n_{R}-n_{\mathrm{G}}\right)}{\left(n_{G+1}-n_{G}\right)}
\end{aligned}
$$

where: $n_{R}$ represents the RTK measurement number, that is, $n_{R}=1, \ldots, n_{R T K}, n_{G}$ represents the GPS measurement number, that is, $n_{G}=1,1+r, \ldots, n_{G P S}$, where $r$ is a RTK to GPS measurement ratio calculated according to the following equation:

$$
r=\frac{n_{R T K}}{n_{G P S}}
$$

An example of a result for the GPS position interpolation is presented in Figure 6. In every case the number of GPS measurements was increased and equals the number of RTK measurements.

\subsection{System Offsets}

The position of the unit for navigation purposes is taken from the navigation GPS placed on the top of the mast located in the geometric center of the USV. The GPS antenna location is determined by experience and typical recommendations for unmanned units; that is, the best place for navigations system is the geometric center of the unit and at the highest possible place to diminish interference with board electronics and ensure best satellite visibility. These actions were taken in the present study.

For the hydrographic equipment, this consisted of a multi beam echosounder (MBES), a precise SGB IMU, and an RTK receiver. The best practice for that equipment localization is that the IMU sensors and the MBES antenna should be as close as possible, if not, all offsets should be entered into the system. In that case, the offsets represent coordinates in the local unit coordinate system of all hydrographic equipment including the GPS, the RTK antennas, and the IMU unit, where the IMU sensor is the coordinate system origin with the $Y$ axis parallel to the unit long axis of symmetry (Figure 8). The hydrographic equipment is calibrated, and offsets are entered into the hydrographic system in accordance with values presented in Table 4. This means that the GPS RTK position was already reported with offsets by the hydrographic system at the origin.

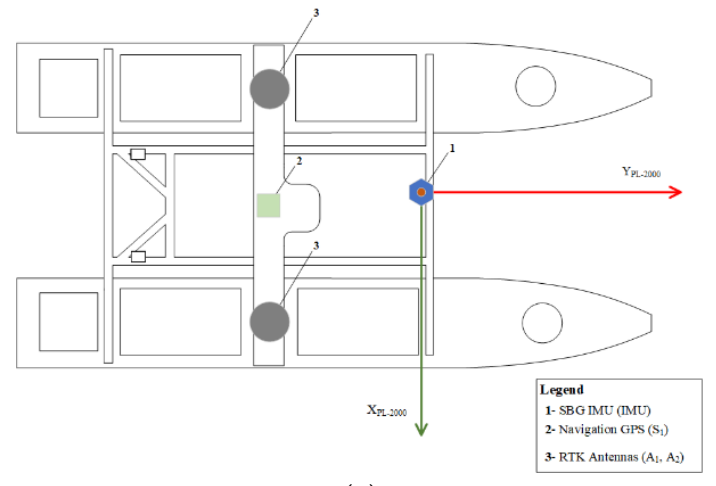

(a)

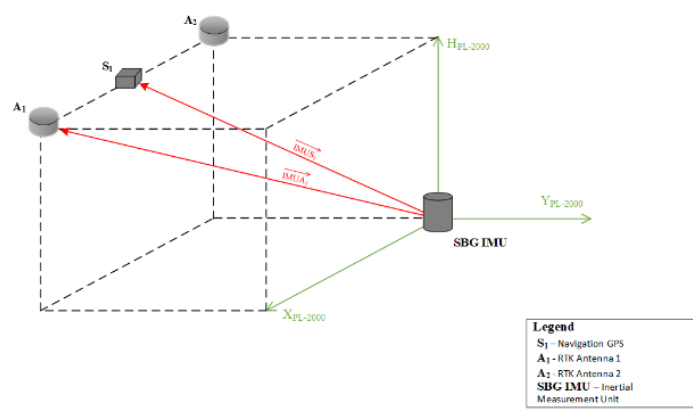

(b)

Figure 8. Measurement equipment location on the unit (a) and local unit coordinate system (b). 
Table 4. Navigation equipment offsets.

\begin{tabular}{ccccccc}
\hline & $\mathbf{d y}$ & $\mathbf{d x}$ & $\mathbf{d}_{\mathbf{H}}$ & $\left|\mathrm{COGA}_{\mathbf{1}}\right|$ & $\left|\mathrm{COGS}_{\mathbf{1}}\right|$ & Remarks \\
\hline GPS & -1.22 & 0.16 & 0.89 & \multirow{2}{*}{16.402} & & For Equations (12) and (13) \\
Origin & 0 & 0 & 0 & & 15.186 & In hydrographic system \\
Antenna RTK 1 & -1.22 & -0.64 & 0.89 & & & In hydrographic system \\
Antenna RTK 2 & -1.22 & 0.96 & 0.89 & & & \\
\hline
\end{tabular}

Given that the system navigation GPS is working out of the hydrographic system and for proper evaluation a vector between the RTK and GPS readings has to be included. The corrected GPS position was calculated from already interpolated GPS positions according to the following formula:

$$
\begin{aligned}
& \hat{\mathrm{X}}_{G_{i}}^{*}=\hat{\mathrm{X}}_{G_{i}}-\left(d_{\mathrm{xG}} \cos \left(H D G_{i}\right)-d_{\mathrm{y} G} \sin \left(H D G_{i}\right)\right) \\
& \hat{\mathrm{Y}}_{G_{i}}^{*}=\hat{\mathrm{Y}}_{G_{i}}-\left(d_{\mathrm{x} G} \sin \left(H D G_{i}\right)+d_{\mathrm{y} G} \cos \left(H D G_{i}\right)\right.
\end{aligned}
$$

where $\hat{\mathrm{X}}_{G_{i}}^{*} \hat{Y}_{G_{i}}^{*}$ are the antenna coordinates of the GPS receiver in the national plane rectangular coordinate system, $d_{\mathrm{xG}}, d_{\mathrm{yG}}$ are the antenna offset values of the GPS antenna unit on the vehicle coordinate system, defined at the center of IMU(RTK) unit with the y axis being parallel to the unit symmetry axis, and the $\mathrm{x}$ axis being perpendicular to the $\mathrm{y}$ axis, and HDG is the vessel's actual course reported by the hydrographic system (Figure 9).

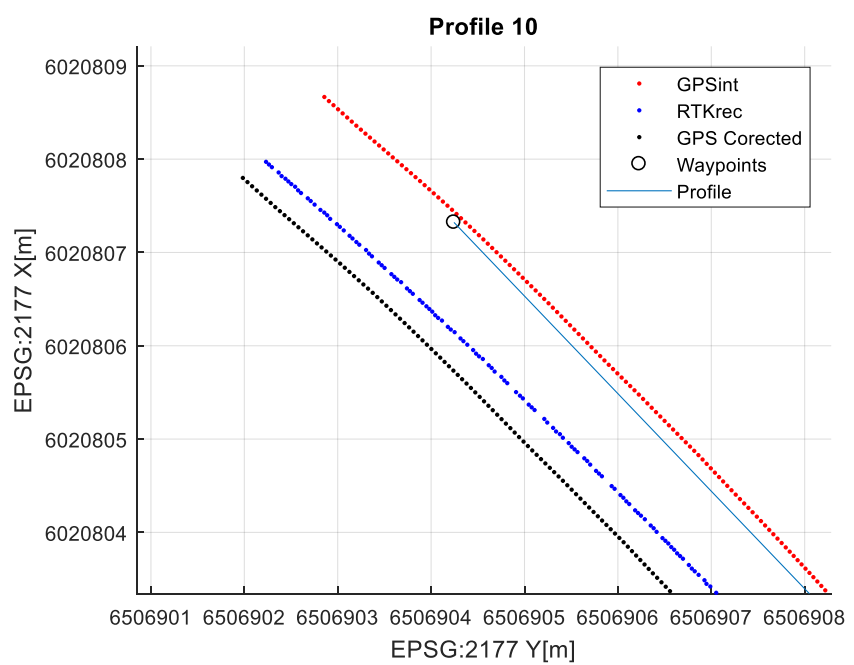

Figure 9. Example of corrected position for GPS at profile no. 10 (black dots).

\subsection{GPS Evaluation}

Having obtained all data at an equal rate, with the same coordinate system (PL-2000) and corrected the coordinates using antenna offsets, the navigation GPS accuracy may be calculated. Initially a Euclidean distance between the navigation GPS interpolated position $\left(\hat{p}_{G P S}\right)$ and the RTK referenced position was calculated, in accordance with following equation:

$$
d\left(\mathrm{p}_{\mathrm{GPS}}, \mathrm{p}_{R \mathrm{TK}}\right)=\sum_{n_{R}=1}^{n_{R}=n_{R T K}} \sqrt{\left(\hat{\mathrm{p}}_{\mathrm{GPS}_{n_{R}}}-p_{R \mathrm{RK}_{n_{R}}}\right)^{2}}
$$

Consequently, the dynamic navigation GPS accuracy was calculated in accordance with formula in [44]. 


\subsection{Cross Track Error}

The cross track error (XTE) is defined as the distance between the planned sounding profile (planned USV track) and the actual unit position. The sounding profiles are represented by a line connecting two defined WPs. Figure 3 presents the XTE, which equals $l_{\perp}$. Assuming that the sounding profile is defined by two waypoints $W P_{i}\left(X_{W_{i}}, Y_{W_{i}}\right)$ and the next waypoint $W P_{i+1}\left(X_{W_{i+1}}, Y_{W_{i+1}}\right)$, and the actual unit position is an interpolated GPS position with coordinates $\hat{\mathrm{p}}_{G_{\mathrm{FS}} n_{R}}\left(\hat{X}_{\mathrm{G}_{\mathrm{i}}}, \hat{Y}_{\mathrm{G}_{\mathrm{i}}}\right)$ at the measurement number $n_{R}$, then the actual XTE can be calculated in accordance with the following formula:

$$
X T E_{n_{R}}=\frac{\left|\left(Y_{W_{i+1}}-Y_{W_{i}}\right) \hat{X}_{G_{i}}-\left(X_{W_{i+1}}-X_{W_{i}}\right) \hat{Y}_{G_{i}}+X_{W_{i+1}} Y_{W_{i}}-Y_{W_{i+1}} X_{W_{i}}\right|}{\sqrt{\left(Y_{W_{i+1}}-Y_{W_{i}}\right)^{2}+\left(X_{W_{i+1}}-X_{W_{i}}\right)^{2}}}
$$

\section{Results}

The final results represent the calculation process outlined above. Each profile was calculated separately. Table 5 is a graphical example of the results for three representative profiles, np. 2, 6, and 10. The coordinates difference graph represents differences for the $X$ and $Y$ coordinates between the RTK and GPS registered positions along the selected profile. The Euclidean distance represents the results of Equation (14) along selected profiles in meters. The XTE represents the cross track error along selected profiles as a result of applying Equation (15).

Table 5. Graphical results for example profiles no. 2, 6, and 10.

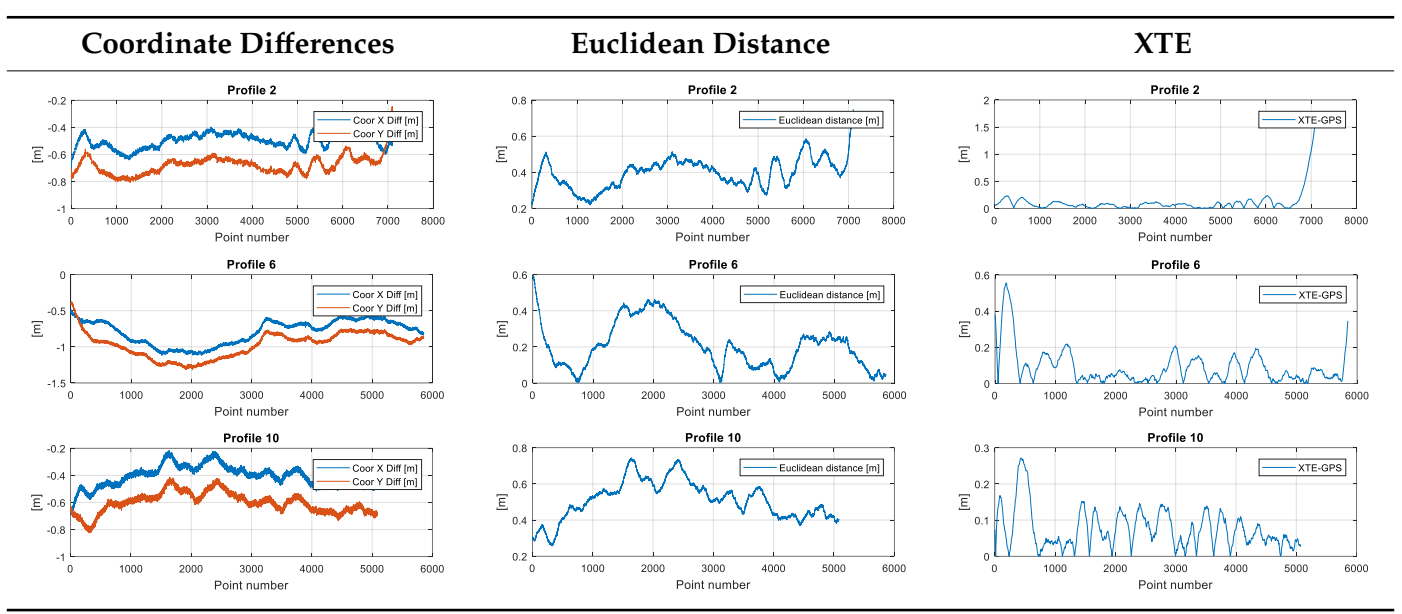

Based on the above calculation, the accuracy of dynamic navigation GPS was calculated in accordance with equations described elsewhere $[44,45]$ for each profile separately. Table 6 presents the results of the calculations for each profile. Additionally, in Table 6 the mean XTE was added to evaluate the accuracy of the trajectory tracking for each profile.

The mean values for the research study are presented in Table 7. The mean accuracy for trajectory tracking (mean unit XTE) of the USV is very satisfactory, particularly if we compare it with traditional manual profile tracking or trajectory tracking realized by a typical autopilot used for ship navigation. 
Table 6. Results for all profiles.

\begin{tabular}{cccccccc}
\hline Profile No. & $\boldsymbol{\sigma}_{\mathbf{x}}$ & $\boldsymbol{\sigma}_{\mathbf{y}}$ & DRMS & 2DRMS & CEP & R95 & Mean XTE \\
\hline 1 & 0.4490 & 0.4788 & 0.6564 & 1.3129 & 0.5483 & 1.1405 & 0.1389 \\
2 & 0.0599 & 0.0698 & 0.0920 & 0.1840 & 0.0768 & 0.1598 & 0.1080 \\
3 & 0.1650 & 0.2108 & 0.2677 & 0.5354 & 0.2231 & 0.4640 & 0.0934 \\
4 & 0.1029 & 0.0977 & 0.1419 & 0.2839 & 0.1182 & 0.2459 & 0.0578 \\
5 & 0.1756 & 0.1975 & 0.2643 & 0.5286 & 0.2208 & 0.4592 & 0.0582 \\
6 & 0.1698 & 0.1770 & 0.2453 & 0.4906 & 0.2048 & 0.4260 & 0.0881 \\
7 & 0.1013 & 0.1447 & 0.1766 & 0.3533 & 0.1464 & 0.3046 & 0.0875 \\
8 & 0.0857 & 0.0853 & 0.1209 & 0.2418 & 0.1009 & 0.2098 & 0.0911 \\
9 & 0.0946 & 0.1044 & 0.1409 & 0.2817 & 0.1177 & 0.2448 & 0.0783 \\
10 & 0.0783 & 0.0773 & 0.1101 & 0.2201 & 0.0918 & 0.1909 & 0.0750 \\
11 & 0.2164 & 0.1547 & 0.2660 & 0.5320 & 0.2171 & 0.4516 & 0.2546 \\
12 & 0.3149 & 0.0575 & 0.3201 & 0.6402 & 0.2120 & 0.4410 & 0.2433 \\
13 & 0.1403 & 0.2244 & 0.2646 & 0.5293 & 0.2177 & 0.4528 & 0.3474 \\
14 & 0.0591 & 0.1475 & 0.1589 & 0.3177 & 0.1245 & 0.2590 & 0.2315 \\
15 & 0.2188 & 0.4595 & 0.5089 & 1.0179 & 0.4074 & 0.8475 & 0.3826 \\
16 & 0.7284 & 0.2069 & 0.7572 & 1.5145 & 0.5362 & 1.1153 & 0.3218 \\
17 & 0.5927 & 0.3553 & 0.6910 & 1.3821 & 0.5522 & 1.1486 & 1.5335 \\
18 & 0.1795 & 0.3014 & 0.3508 & 0.7016 & 0.2874 & 0.5977 & 1.1249 \\
19 & 0.1899 & 0.5650 & 0.5961 & 1.1922 & 0.4567 & 0.9499 & 0.4945 \\
\hline
\end{tabular}

Table 7. Mean accuracy results for USV configuration.

\begin{tabular}{cccccccc}
\hline & $\sigma_{\mathbf{x}}$ & $\sigma_{\mathbf{y}}$ & DRMS & 2DRMS & CEP & R95 & Mean Unit XTE \\
\hline Mean & 0.2170 & 0.2166 & 0.3226 & 0.6452 & 0.2558 & 0.5321 & 0.3058 \\
\hline
\end{tabular}

\section{Discussion}

Nonlinear guidance, originally designed for UAV trajectory tracking, has been adopted and used for USV trajectory tracking. This method allows us to keep a low XTE during all sounding profiles' tracking; more importantly, the USV course changes that keep to the track are very gentle, and do not cause significant disturbances in hydrographic measurements. The trajectory tracking and the USV response for the calculated course inputs depend on the correct PID tuning. As stated above, PID tuning was carried out during extensive field tests. The configuration employed did not show any oscillations, the course changes although robust were gentle, allowing us to keep track within specified limits for the unit to weather conditions and wind direction. The correct PID tuning is very important for course and track keeping. As mentioned elsewhere [28], the USV used in this research showed a regular oscillation for track following, caused by not having ideal PID tuning, and this can significantly affect the unit's endurance and the quality of hydrographic measurement.

The position registered by the navigation GPS is not used directly by the USV for navigation. The pure GPS position readings are filtered using EKF and the final navigation position is calculated using all data available to the autopilot internal sensors. This technique is used widely within the robotics community to estimate a robot's position. Consequently, the position used for navigation, as the results show, has good accuracy. The profile planned by the hydrographers, was followed based on GPS position. If we take into account the antenna position (in the center of the unit) and the offsets between the GPS antenna and the multibeam sonar (main hydrographic sensor) this causes quite significant differences between the real unit track and the sonar antenna track. The displacement differs and depends on the wind speed and direction. Practically, the profile is registered by the RTK system with offsets, therefore, from the hydrographic point of view, all data are registered correctly, however this difference can be diminished. 


\section{Conclusions}

As the results show, the accuracy of trajectory tracking based on nonlinear guidance logic is suitable for hydrographic USV profile tracking, and the presented unit configuration permits very precise track following with a mean XTE of around $30 \mathrm{~cm}$. This is a very good result, if we compare this performance with a traditional manned hydrographic vessel. In the authors' opinion, trajectory tracking based on nonlinear guidance logic for hydrographic measurements can be implemented on a wide variety of USVs providing correct nonlinear guidance logic and PID parameters.

The difference between the track realized by the unit and the real sonar track can be significant and depends on wind speed and direction. This difference can be diminished using either software offsets or antenna physical displacement. The other approach is to use the RTK signal directly for navigation during the hydrographic survey.

Author Contributions: Conceptualization, A.S. and P.B.; methodology, A.S. and P.B.; bibliography review, A.S., P.B. and B.D.-S.; acquisition, analysis, and interpretation of data, A.S., P.B. and K.N., writing-original draft preparation, A.S. and P.B.; writing-review and editing, A.S., P.B., K.N. and B.D.-S. All authors have read and agreed to the published version of the manuscript.

Funding: This research was funded by the European Regional Development Fund under the 2014-2020 Operational Programme Smart Growth as part of the project "Developing of autonomous/remote operated surface platform dedicated hydrographic measurements on restricted reservoirs" implemented as part of the National Centre for Research and Development competition, INNOSBZ.

Conflicts of Interest: The authors declare no conflict of interest. The funders had no role in the design of the study; in the collection, analyses, or interpretation of data; in the writing of the manuscript, or in the decision to publish the results.

\section{References}

1. Specht, M. Method of Evaluating the Positioning System Capability for Complying with the Minimum Accuracy Requirements for the International Hydrographic Organization Orders. Sensors 2019, $19,3860$. [CrossRef] [PubMed]

2. Wang, N.; Er, M.J. Direct Adaptive Fuzzy Tracking Control of Marine Vehicles with Fully Unknown Parametric Dynamics and Uncertainties. IEEE Trans. Contr. Syst. Technol. 2016, 24, 1845-1852. [CrossRef]

3. Wang, N.; Er, M.J.; Sun, J.; Liu, Y. Adaptive Robust Online Constructive Fuzzy Control of a Complex Surface Vehicle System. IEEE Trans. Cybern. 2016, 46, 1511-1523. [CrossRef] [PubMed]

4. Liu, T.; Dong, Z.; Du, H.; Song, L.; Mao, Y. Path following control of the underactuated USV based on the improved line-of-sight guidance algorithm. Pol. Marit. Res. 2017, 24, 3-11. [CrossRef]

5. Liao, Y.; Wan, L.; Zhuang, J. Back stepping dynamical sliding mode control method for the path following of the underactuated surface vessel. Procedia Eng. 2011, 15, 256-263. [CrossRef]

6. Dong, Z.; Wan, L.; Li, Y.; Liu, T.; Zhang, G. Trajectory tracking control of underactuated USV based on modified backstepping approach. Int. J. Nav. Archit. Ocean Eng. 2015, 7, 817-832. [CrossRef]

7. Fan, Y.; Mu, D.; Zhang, X.; Wang, G.; Guo, C. Course keeping control based on integrated nonlinear feedback for a USV with pod-like propulsion. J. Navig. 2018, 71, 878-898. [CrossRef]

8. Huang, Q.; Li, T.; Li, Z.; Hang, Y.; Yang, S. Research on PID control technique for chaotic ship steering based on dynamic chaos particle swarm optimization algorithm. In Proceedings of the 10th World Congress on Intelligent Control and Automation, Beijing, China, 6-8 July 2012; pp. 1639-1643.

9. Li, Y.; Yang, S.; Yu, Y.; Liu, M. Study on optimization and simulation of hydrofoil USV propulsion intelligent control based on chaos algorithm. In Proceedings of the 2017 2nd International Conference on Materials Science, Machinery and Energy Engineering (MSMEE 2017), Dalian, China, 13-14 May 2017. [CrossRef]

10. Huang, Q.; Liu, X.; Li, T.; Wang, K.; Wang, S. On impulsive parametric perturbation control techniques for chaotic ship steering. In Proceedings of the Proceedings of 2014 IEEE Chinese Guidance, Navigation and Control Conference, Yantai, China, 8-10 August 2014; pp. 428-433.

11. Wang, N.; Sun, J.; Er, M.J. Tracking-Error-Based Universal Adaptive Fuzzy Control for Output Tracking of Nonlinear Systems with Completely Unknown Dynamics. IEEE Trans. Fuzzy Syst. 2018, 26, 869-883. [CrossRef] 
12. Wang, N.; Su, S.; Yin, J.; Zheng, Z.; Er, M.J. Global Asymptotic Model-Free Trajectory-Independent Tracking Control of an Uncertain Marine Vehicle: An Adaptive Universe-Based Fuzzy Control Approach. IEEE Trans. Fuzzy Syst. 2018, 26, 1613-1625. [CrossRef]

13. Patino, H.D.; Liu, D. Neural network-based model reference adaptive control system. IEEE Trans. Syst. Man Cybern. Part B (Cybern.) 2000, 30, 198-204. [CrossRef]

14. Dai, S.-L.; Wang, C.; Luo, F. Identification and learning control of ocean surface ship using neural networks. IEEE Trans. Ind. Inform. 2012, 8, 801-810. [CrossRef]

15. Zhang, Y.; Hearn, G.E.; Sen, P. A neural network approach to ship track-keeping control. IEEE J. Ocean. Eng. 1996, 21, 513-527. [CrossRef]

16. Brown, M.; Harris, C.J. Neurofuzzy Adaptive Modelling and Control; Prentice Hall: Upper Saddle River, NJ, USA, 1994.

17. Wang, N.; Joo Er, M. Self-Constructing Adaptive Robust Fuzzy Neural Tracking Control of Surface Vehicles with Uncertainties and Unknown Disturbances. IEEE Trans. Control Syst. Technol. 2015, 23, 991-1002. [CrossRef]

18. Wang, N.; Sun, J.; Er, M.J.; Liu, Y. A Novel Extreme Learning Control Framework of Unmanned Surface Vehicles. IEEE Trans. Cybern. 2016, 46, 1106-1117. [CrossRef] [PubMed]

19. Wang, N.; Karimi, H.R.; Li, H.; Su, S. Accurate Trajectory Tracking of Disturbed Surface Vehicles: A Finite-Time Control Approach. IEEE/ASME Trans. Mechatron. 2019, 24, 1064-1074. [CrossRef]

20. Wang, N.; Qian, C.; Sun, J.; Liu, Y. Adaptive Robust Finite-Time Trajectory Tracking Control of Fully Actuated Marine Surface Vehicles. IEEE Trans. Control Syst. Technol. 2016, 24, 1454-1462. [CrossRef]

21. Wang, N.; Pan, X. Path Following of Autonomous Underactuated Ships: A Translation-Rotation Cascade Control Approach. IEEE/ASME Trans. Mechatron. 2019, 24, 2583-2593. [CrossRef]

22. Stateczny, A.; Burdziakowski, P. Universal autonomous control and management system for multipurpose unmanned surface vessel. Polish Marit. Res. 2019, 1, 30-39. [CrossRef]

23. Stateczny, A.; Kazimierski, W.; Gronska-Sledz, D.; Motyl, W. The Empirical Application of Automotive 3D Radar Sensor for Target Detection for an Autonomous Surface Vehicle's Navigation. Remote Sens. 2019, 11, 1156. [CrossRef]

24. Park, S.; Deyst, J.; How, J. A new nonlinear guidance logic for trajectory tracking. AIAA Guid. Navig. Control Conf. Exhib. 2004. [CrossRef]

25. Guo, W.; Wang, S.; Dun, W. The Design of a Control System for an Unmanned Surface Vehicle. Open Autom. Control Syst. J. 2015, 7, 50-156. [CrossRef]

26. Moreno, D.; Chaos, D.; Aranda, J.; Muñoz, R.; Díaz, J.M.; Dormido-Canto, S. Application of an aeronautic control for ship path following. J. Marit. Res. 2009, 6, 71-82.

27. Specht, C.; Specht, M.; Cywinski, P.; Skóra, M.; Marchel, Ł.; Szychowski, P. A New Method for Determining the Territorial Sea Baseline Using an Unmanned Hydrographic Surface Vessel. J. Coast. Res. 2019, 35, 925-936. [CrossRef]

28. Specht, M.; Specht, C.; Lasota, H.; Cywinski, P. Assessment of the Steering Precision of a Hydrographic Unmanned Surface Vessel (USV) along Sounding Profiles Using a Low-Cost Multi-Global Navigation Satellite System (GNSS) Receiver Supported Autopilot. Sensors 2019, 19, 3939. [CrossRef]

29. Seto, M.L.; Crawford, A. Autonomous shallow water bathymetric measurements for environmental assessment and safe navigation using USVs. In Proceedings of the OCEANS 2015-MTS/IEEE Washington, Washington, DC, USA, 19-22 October 2015.

30. Alessandri, A.; Donnarumma, S.; Martelli, M.; Vignolo, S. Motion Control for Autonomous Navigation in Blue and Narrow Waters Using Switched Controllers. J. Mar. Sci. Eng. 2019, 7, 196. [CrossRef]

31. Munoz-Banon, M.; del Pino, I.; Candelas, F.; Torres, F. Framework for Fast Experimental Testing of Autonomous Navigation Algorithms. Appl. Sci. Basel 2019, 9, 1997. [CrossRef]

32. Kunicka, M.; Litwin, W. Energy Demand of Short-Range Inland Ferry with Series Hybrid Propulsion Depending on the Navigation Strategy. Energies 2019, 12, 3499. [CrossRef]

33. Borkowski, P. Adaptive System for Steering a Ship along the Desired Route. Mathematics 2018, 6, 196. [CrossRef]

34. Borkowski, P. Inference Engine in an Intelligent Ship Course-Keeping System. Comput. Intell. Neurosci. 2017. [CrossRef] 
35. Li, C.; Jiang, J.; Duan, F.; Liu, W.; Wang, X.; Bu, L.; Sun, Z.; Yang, G. Modeling and Experimental Testing of an Unmanned Surface Vehicle with Rudderless Double Thrusters. Sensors 2019, 19, 2051. [CrossRef]

36. Zhan, W.; Xiao, C.; Wen, Y.; Zhou, C.; Yuan, H.; Xiu, S.; Zhang, Y.; Zou, X.; Liu, X.; Li, Q. Autonomous Visual Perception for Unmanned Surface Vehicle Navigation in an Unknown Environment. Sensors 2019, 19, 2216. [CrossRef] [PubMed]

37. Lisowski, J. The sensitivity of state differential game vessel traffic model. Polish Marit. Res. 2016, 23, 14-18. [CrossRef]

38. Dudojc, B.; Mindykowski, J. New Approach to Analysis of Selected Measurement and Monitoring Systems Solutions in Ship Technology. Sensors 2019, 19, 1775. [CrossRef] [PubMed]

39. Li, J.; Du, J.; Sun, Y.; Lewis, F.L. Robust adaptive trajectory tracking control of underactuated autonomous underwater vehicles with prescribed performance. Int. J. Robust Nonlinear Control 2019, 29, 4629-4643. [CrossRef]

40. Paliotta, C.; Lefeber, E.; Pettersen, K.; Pinto, J.; Costa, M.I.C.; de Sousa, J.T.D.B. Trajectory Tracking and Path Following for Underactuated Marine Vehicles. IEEE Trans. Control Syst. Technol. 2019, 27, 1423-1437. [CrossRef]

41. GITHUB. Available online: https://github.com/ArduPilot/ardupilot/commit/a3c2851120f3572893bdf29ddc0e e24dac67cbe1 (accessed on 12 December 2019).

42. Jang, T.; Han, S. Analysis for VTOL Flight Software of PX4. In Proceedings of the 2018 18th International Conference on Control, Automation and Systems (ICCAS), Daegwallyeong, South Korea, 17-20 October 2018; pp. 872-875.

43. Siauw, T.; Bayen, A. An Introduction to MATLAB ${ }^{\circledR}$ Programming and Numerical Methods for Engineers; Academic Press: Cambridge, MA, USA, 2015. [CrossRef]

44. Specht, C.; Dabrowski, P.S.; Pawelski, J.; Specht, M.; Szot, T. Comparative analysis of positioning accuracy of GNSS receivers of Samsung Galaxy smartphones in marine dynamic measurements. Adv. Space Res. 2019, 63, 3018-3028. [CrossRef]

45. NovAtel Positioning Leadership. GPS Position Accuracy Measures. APN-029 Revision 1. 2003. Available online: https://www.novatel.com/assets/Documents/Bulletins/apn029.pdf (accessed on 12 December 2019).

(C) 2020 by the authors. Licensee MDPI, Basel, Switzerland. This article is an open access article distributed under the terms and conditions of the Creative Commons Attribution (CC BY) license (http://creativecommons.org/licenses/by/4.0/). 